\title{
Hybrid determinant model of the coffee entrepreneurship
}

Martínez Muñoz, Enrique

Universidad Autónoma del Estado de Hidalgo, México

enriquemarmun@gmail.com

Sánchez Sánchez, Arturo

Universidad Autónoma de Tlaxcala, México artuross1@hotmail.com

Anguiano Salazar, Fermín Universidad Autónoma de la Ciudad de México, México

García Lirios, Cruz Universidad Autónoma del Estado de México, México garcialirios@yahoo.com
Carreón Guillén, Javier

Universidad Nacional Autónoma de México, México javierg@unam.mx

Espinoza Morales, Francisco

Universidad de Sonora, México francisco.espinozamorales@unison.mx

Bucio Pacheco, Christian

Universidad Nacional Autónoma de México, México

cbuciop@uaemex.mx

Quintero Soto, María Luisa

Universidad Nacional Autónoma de México, México

quinluisa@yahoo.com.mx
Abstract - The exploration of the relationships between the determinants of entrepreneurship was the objective of this work. A non-experimental study was carried out with a non-probabilistic selection of 300 coffee farmers affiliated to the microfinance program. Is observed a structure of five factors: representations, habitus, fields, capital, capabilities and enterprise that explained $54 \%$ of the total variance explained, although the research design limited findings local scenario, suggesting the inclusion of variables that the literature identifies sociodemographic and socioeconomic variables to establish entrepreneurial profiles according to risk events; landslides, fires, droughts, floods, frosts or earthquakes.

Keywords: Coffee growing; entrepreneurship; heads of family; model; microenterprise;
Resumen - La exploración de las relaciones entre los determinantes del emprendimiento fue el objetivo de este trabajo. Se llevó a cabo un estudio no experimental con una selección no probabilística de 300 productores de café afiliados al programa de microfinanzas. Se observa una estructura de cinco factores: representaciones, habitus, campos, capital, capacidades y empresa que explicaron el $54 \%$ de la varianza total explicada, aunque el estudio de investigación limitó los hallazgos del escenario local, sugiriendo la inclusión de variables que la literatura identifica sociodemográficas y socioeconómicas. variables para establecer perfiles empresariales de acuerdo con eventos de riesgo; Deslizamientos, incendios, sequías, inundaciones, heladas o terremotos.
Interconectando Saberes, 2019

ISSN: 2448-8704
Fecha de Recepción: 12 de marzo de 2019

Fecha de Aceptación: 22 de agosto de 2019

Fecha de Publicación: 31 de octubre de 2019 
Palabras clave: Crecimiento del café; emprendimiento; jefes de familia; modelo; microempresa;

\section{INTRODUCTION}

The purpose of this study is to explore the relationships between key variables of entrepreneurship according to a review of the literature: theory of social representation theory of habitus, theories of capital, field theory and theories of capacities, considering that it is theoretical corpus explaining the phenomenon in the face of local risk events such as floods, landslides, earthquakes, fires, frosts or droughts, together with corruption; Nepotism, opacity, impunity or negligence intensify the barriers to local development and encourage the innovation of organized sectors such as coffee growers.

Of course, entrepreneurship involves representations, habitus, fields and capital; this around the production, marketing and business training. In a certain sense, the objectification and anchoring, essential processes of social representations, explain the trans- formation of knowledge and knowledge in common sense, more precisely, heuristics from which the logic of supply and demand fades into affects or feelings about Orient time and money to produce coffee (Amrouni and Abdelwahed, 2014).

However, not only knowledge is disrupted by entrepreneurial forces, but also adjusted to local ecotourism dynamics. In this sense, discourse among other elements is the means to build predispositions around coffee growing. This is how, through social representations, coffee is transformed into discursive habits from which local conventions based on global conventions are based, since micro-enterprises, being linked to transnationals, adopt organizational forms and discourses to foster entrepreneurial spirit in inhabitants of "magical towns" as in the case of the huasteca region in Xilitla, San Luis Potosí, Mexico (Berrou and Combaunous, 2012).

It is a process in which the symbols, meanings and meanings are categorized in images that impact 
the interpretation and personal action, although this process is disseminated to groups and organizations related to coffee. This makes possible the social distinction of an entrepreneurial sector in reference to the community, but even in reference to the other farming groups in the Huasteca region (Caballo, Reyes and Solis 2006).

From a discursive level, it is not only possible to differentiate the symbols or meanings in their temporal or spatial environments, but also to anticipate the diversity of expectations that are generated after a business activity has been erected as a hallmark of a community in clear allusion to industry, commerce, tourism or poverty, marginalization, vulnerability or exclusion. Such dimensions are condensed in propensity or aversion to the future because, while social representations are connected with the past and the future, they generate predispositions of risk around which sowing, and harvesting are planned. That is, the representation of coffee farming seems to circumscribe preferences, actions, feelings or thoughts which constitute dis- courses that delimit fields of expectations and generate relations of cooperation and trust (Carr and Sequeira, 2007).

This question implies five explanatory theoretical frameworks of the imbrication of coffee production in the discourses of producers and traders. The Theory of Social Representations, being a process of communication of innovations with respect to coffee growing, infiltrates the symbols and meanings that microentrepreneurs build. Once these have infiltrated images and words, they are now recovered as a repertoire of knowledge regarding the always or coffee harvest (Carreon 2016).

If a representation links coffee farming with other personal or community needs, then it supposes provisions that facilitate the objectification or anchoring of information related to sowing, harvesting, weather, pests, prices and prices. If such arrangements have been transferred from generation to generation then a longitudinal study would account for the representations, objectification and anchoring, 
as well as their habitus, inherited or acquired, over a relatively transient period in which the community went from being migrant to microentrepreneur (Carreon, 2013).

This is how the Theory of Discursive Habitus focuses the explanation efforts on those symbols from which symbols can be derived, grouped and resignified while demonstrating a way of thinking, acting and feeling that would distinguish Xilitla, SLP, from other indigenous peoples or magical dedicated, in particular, to coffee (Carreón, Hernández, Quintero, García and Mejía, 2016).

In this regard, the Theory of Fields of Power argues that the conflicts arising from the asymmetric distribution of inputs for coffee cultivation is the driving force behind the changes that are taking place in the production and commercialization of coffee in the microregion (Carreón, De la Cruz and De los Santos, 2015).

However, such transformation seems to be more discursive because while the migrants of Xilitla re- turn, groups of merchants are given the task of undertaking new projects and business plans that involve the dissemination of the town as a place of tourism and recreation rather than production and sale of coffee. At the level of symbols, it is necessary to understand the discursive relationships between those who create jobs and those who diversify them with the diffusion of community innovations such as ecotourism, organic production, crafts and typical food (Castiglioni, Castro and Galán, 2015).

This process of diversification and imbrication of coffee is focused on the formation of collaborative networks that are not only discursive. These are processes of trust in which the cooperation between families of coffee farmers makes feasible their analysis as social capital, in which knowledge is no longer just a matter of management, but of representation, habitus and empowerment (Contreras, 2012).

In this way, Xilitla assumes itself as a prosperous economic entity because it is anchored in discourses that deal with entrepreneurship, 
commerce and progress. That is to say, at least the community no longer presents symptoms of discursive or economic impoverishment. The people who live in this microregion assume responsibility for their own destiny and act accordingly. They carry out actions motivated by the social differentiation that implies being a migrant, trader, coffee grower or micro-entrepreneur (Domínguez and Fuentes, 2006).

However, the process would be incomplete if we did not recognize the opportunities in line with the abilities and responsibilities of the inhabitants of Xilitla for their future generations and other networks of social capital that act in favor of community progress or at least distancing with poverty. The Theory of Economic Capacities in consonance with the freedoms of choice for the covering of the social fabric in terms of employment, health and education, assumes that individuals are agents of knowledge and management whose capacities allow the dissemination of responsibilities to the groups in those who are immersed (Fernández and Crespo, 2011).
Precisely, it is at this point, where the symbols and meanings regarding coffee growing are linked to scenarios of collaboration and transfer of knowledge that allow traders to enter a local market. It is here where the knowledge that enables the differentiation of coffee growing in sowing, harvesting, refining, packaging, logistics, distribution, preparation and sale seems to emerge. The new generations of coffee farmers have not only objectified or anchored knowledge, but have also assumed it as part of their lifestyles and discursive ways (Ferreiro, 2013).

Faced with the environmental problems of droughts or floods, social capital networks in Xilitla respond with organization of the crop in diversified stages, but confined to the achievement of goals that guarantee the productive cycle. Furthermore, the productive process is complemented with the management and promotion of coffee growing in other localities of the region and beyond it as a tourist entity. This is the key to the economic success and prosperity in Xilitla, of 
which remittances are still a fundamental part of the economic dynamics, but it is the symbolic capital that drives social, political and economic relations. Entrepreneurship culture or the entrepreneurial spirit of Xilitla undermines poverty and encourages entrepreneurial and labor skills to stabilize representations, habitus, fields and capitals related to coffee growing (Fuentes and Sánchez, 2010).

The representations are discursive innovations from which scientific knowledge is disseminated in common sense and social thought, although this is exclusive of not only science, art or culture in general since the symbols to discover or invent are also prone to its transformation into interpretations of reality and more primarily discursive senses. However, social representations, being communicative, move away from individual cognition and approach the asymmetric relationships of the groups. Once the scientific information is available, the groups are responsible for socializing their contents. For this purpose, a differentiation between the groups will be necessary in order to establish the conflicts that lead them to anticipate changes (Loui, Carpio and Vergara, 2012).

The groups are divided into minorities and majorities around surrounding information that allows them to represent prototypes of behavior to build an identity. In such a scenario, the perception of justice disseminates the legitimacy of decisions. However, the transfer of public information becomes part of the personal knowledge repertory . This is so because information is a means of spreading asymmetric relations between groups and individuals, but suppose that the group dynamics is imbricated as well as the individual in an object of representation that when it is not social is cultural or at least contextual implies a reduction of symbols to expectations, abilities or attitudes (García, Carreón, Hernández and Salinas 2016).

Rather, social representations are observable interpretations, but this does not suggest that these can be symptoms of perceptions, beliefs, motives or knowledge since they are conventions or discrepan- 
cies, but they cannot be indicators of individual processes. That is why social representations facilitate and inhibit the insertion of symbols in the individual cultural repertoire, but above all in the images that we share or want to dissuade. It is a figurative core and a peripheral set of concrete actions where the ideological components are enveloped by an emerging periphery of common symbols and mainstream (Garcia, Carreon Hernandez Aguilar, Rosas and Bustos, 2015).

The process that goes from the abstract in particular is known as objectification and the symbols that are incorporated into the discursive repertoire is called anchoring, however, being the representation an organization of the symbols shared by a group, objectification confines such symbols to words that have a closer meaning to the experience and lifestyle group that adopts or assigns images such assertions of knowledge, but ends up joining as perceptual signals, attitudinal traits or symptoms provisions (García, Carreón, Hernández, Carbajal, Quintero, Sandoval and Valdés, 2016).
In the case of anchoring, it is a complementary process of incorporating symbols into the perceptual or attitudinal file of the individual, but the anchoring implies a defense through those same symbols that were incorporated in the past and that now compete for the control of decisions and personal actions. In this sense, concretion, regulation and defense are constituted as fundamental elements of social representations, although they occur in the human mind, in reality they are conventions, not to say constructions of reality that when shared by a group organize not only people, but to its environment. That is, social representations are organizations of reality that impacts the individual and the group, but it is a social work that because we are invisible we think that it is transformed into images, but it is enough to change the context to account for the diversity of representations (García, Carreón, Hernández, Montero and Bustos, 2012).

In this way, in a context in which symbols are oriented by social representations and meanings by their processes of objectification and anchoring; the senses or direc- 
tions of symbols and meanings are guided by the defense of representations that, in the face of conflicts and changes, have an impact on their centrality, because the periphery is so abrupt that it reveals an interrelation with centrality and this leads to the supposition that social representations are actually they are interpretations rather than communication, cognition or persuasion; they are in a word: information, which can be biased to transform uses and co- attributes (García, Carreón, Mecalco, Hernández, Bautista and Méndez, 2014).

In the case of migration and entrepreneurship, their social representations seem to be confined to a short-term dynamic, since the costs and benefits are the ones that would most modify the centrality of social representation. That is to say, before loans, credits, financing, investments and other economic support, migrants, traders and coffee growers are exposed to making their decisions no longer from their common sense, but from the balance between their income and expenses (García, Carreón , Sandoval, Bustos and Aguilar, 2016).
According to the state of knowledge, migration and entrepreneurship are psychological and social processes explained from the social representation, organizational image, trust, leadership, commitment, capital, habitus and satisfaction. From the state of the matter, it is possible to anticipate a reflective model to illustrate the central and peripheral social representations around coffee growing in Xilitla, San Luis Potosí, Mexico. Rather, social representations only explain the contexts of migration and entrepreneurship, but they do not clarify their permanence. That is, why Mexico is a country that expel migrants and now why it becomes a country of entrepreneurs are issues that can only be explained from the Theory of Discursive Habitus (Manktelow, 2014).

The concept of habitus alludes to a set of anchored dispositions, if one wants to relate to social representations, in the nucleus or centrality of a context. As a system of dispositions, they are indicated by associations between people, behaviors, feelings, opportunities, capacities, responsibilities or freedoms (Obrego, 2008). 
However, their psychological symptoms are only part of sociological dimensions from which it is possible to notice differences between groups, communities, societies, cultures or generations. It is about relationships between structures, beliefs, norms and values, which may be in organizations or institutions, but not being exclusive of such contexts opens the possibility that habitus are in themselves contexts of scenarios. In such a process, the discursive habitus is linked to practices that enhance the differences between individuals since they can act under the same context, but the meaning or resignification of spaces, objects or people is different. This is so because habitus are the product of asymmetries, discrepancies, controversies, disagreements or tensions that may be of short duration, although they may be extended given the magnitude of the conflict and above all, the influence of the context (Pariente, 2006).

The certain thing is that a context impacts actions, feelings, perceptions and thoughts of a more lasting way because it infiltrates in the structure of the discursive abilities and when being naturalized, following the speech of the social representations, no longer they are only in the periphery, but they have been incorporated into the central nucleus. That is, the habitus is the result of the penetration of the context in the cultural repertoire of individuals and having infiltrated the concepts of defense have managed to become familiar with the central elements (Ramos, 2013).

Habitus are essentially a consequence of the context in outline form and organization of symbols. This duality makes it more feasible to recognize the complexity of the context since habitus are its indicators. It is a context, in terms of human life, short since they are structures inherited and / or learned in the first years of life. This process reveals a dimension of sociohistorical nature of the habitus, and,therefore, another sociopolitical dimension consisting of the socialization of the schemes and structuring of the provisions which, if it were a dialectical process, but it is not because it is rather the influence of context in personal schemes (Robles, Alviter, Ortega, and Martínez, 2016). 
Like the social representations that defend the emergence of other symbols, the habitus will not repair in counteracting the influence of other habitus while defining the actions to be followed according to the contexts to be deterred since new events would imply a diversity of responses, but such resources are rather homogeneous because each person incorporated a system of symbols, meanings and meanings that differentiate them from other people or from themselves under similar or diametrically different circumstances (Rodríguez, 2009).

The habitus comes from the past located in childhood, but also to be acquired and not just inherited, assumes emerging provisions that indicate the penetration of context in the structure of provisions. In the case of migration and entrepreneurship, the habitus explains the process by which a society moves from expellers to traders. This, of course, goes beyond the influence of the context in the communities or individuals, supposes the incidence of public policies related to tourism since the Huasteca community of Xilitla obtains its income from the promotion of its ecotourism space, mountainous areas and wooded areas as well as their uses and coffee habits. In this way, the habitus of the community past explains the migration since in their desire to build a heritage the residents of $\mathrm{Xi}$ litla had to seek employment outside their territory (Urquiza and Cadenas, 2015).

Once a patrimony was built, the exmigrants returned to their community to establish the discourses acquired abroad and that it is possible to identify as a process of entrepreneurship if it is assumed that for such purpose a climate of trust, commitment and satisfaction was generated. That is, the new generations of entrepreneurs are the result of a generation that inherited a migratory habitus and / or transformed into an enterprising habit, but such a process had to take place in a context in which business promotion policies were strategically oriented towards tourism and its derivatives (Carreón, 2016).

The sociohistorical premise of the habitus is thus fulfilled, according to which a conjuncture is the 
result of a structure, although not entirely influenced, if it has been changed in its foundations since the community of Xilitla is now entrepreneurial. The resurfacing of its streets, the remodeling of its buildings, the relocation of its waste, the financing of its trade and the investment in hotel, restaurant and road infrastructure suggest that the community is committed to tourism as an alternative to progress and prosperity, but there is a coffee sector that has managed to insert itself into the migrant habitus and now into the new entrepreneurial dynamic, since it employs other workers from surrounding villages and markets with other groups of coffee farmers in the Huasteca region (Carreón, J., Hernández, J., Bustos and García, 2017).

Although it is true that the $\mathrm{mi}-$ grant and entrepreneurial habitus are discourses related to the search for opportunities, capacities and responsibilities, it is striking that in the case of the migrant habitus, emotions predominate over the actions or deliberations that correspond to the entrepreneurial habitus. That is to say, the differentiation between one habitus and the other is that the economic situation prevented the realization of innovations and oriented the actions to migration, whereas in the current situation the minimum factors for the realization of projects that are financed by the State seem to be combined. Through the Ministry of tourism and work, but are accepted and developed by the Joint (Carreon, Hernández, Quintero Garcia and Mejia, 2016).

However, at the same time that an entrepreneurial habitus was forged, the resources were redistributed, mainly the speeches and their symbolic assets that gave rise to power scenarios without which it would be impossible to explain the differences between day laborers and coffee growers, authorities and citizens, politicians and merchants. A field of power is the equivalent of one of electromagnetic character, since it denotes a space built by internal forces in reference to external forces. However, a field of power is symbolic rather than physical or magnetic, but it works in a similar way because it attracts oneself and expels strangers. However, a power field only reflects asymmetric relations with goods or symbolic 
capitals that structure groups in the face of conflicts that differentiate them from other communities .In this way, the power fields are linked to representations and habitus when circumscribing the anchoring and defense of symbols, but unlike these, the power fields reflect asymmetries and therefore are assumed as a cause of the representations and habitus (García, 2013).

More than socialization of differences, the fields of power are the interrelation of resources or capital that define the power of one group over others similar in their habits or Representation. In this sense, if a field of power emits symbols that will be signified by individuals, then they are areas in which the defense of representations and habitus predominates over the production of symbols. $T$ he symbolic defense scenarios indicate the professional activity of a group. It is a deliberate space in which the production of symbols is confined to the defense of said territory rather than its signification or change. In the case of migration, a power field is inferred by the discourse around the journey, the permanence or the return. That is, migrants build symbols to defend their lifestyle as migrants, unlike those who reside with all individual rights and guarantees (García, 2017).

However, the migrants build a field of power not to preserve their ways of living together, but to protect themselves from other discourses that imply the abandonment of their roots and the cutting of remittances for their families. That is why so the amount of remittances exceeds other sources of income such as tourism, but also migration seems to be supported by networks or symbolic capital goods migrants carry with them whenever recount their experiences. In contrast, the entrepreneurial spirit seems to be configured from multiple spaces of power. When less coffee growers, intermediaries and vendors build speeches based on the distribution of their interactive spaces. Think of the farmers who delimit their actions and speeches to sowing and harvesting, naturally they are at a disadvantage with respect to those who manage their financial, logistical or productive resources (García, Carreón and Hernández, 2016). 
However, a field of power is symbolic and as such, it is understood that the conflicts and changes that occur in it are also. That is why, in the face of droughts and floods, the symbols of power that are at stake refer to forecasts and strategies related to technologies and knowledge management. That is, whoever accesses specialized information has control over the symbolic field of power. Some rituals linked to the journey, the permanence and the return can be observed as indicators of the field of power relative to migration. In the opposite case, the indicators of entrepreneurship, as a field of power, would be materialized in deliberate or heuristic, planned or improvised, systematic or automatic knowledge and knowledge. That is, while migrants use affect and emotions as scenarios of influence, merchants allude to administrative or legal knowledge to differentiate themselves from other economic groups with which they compete (García, Carreón, Bustos and Hernández, 2017).

It is precisely here that the community Xilitla referring to other surrounding built allusive speeches to generating opportunities and capa- cities for responsible social and environmental growth. This implies elements related to their assets or symbolic capital. The concept of capital is equivalent to that of goods or resources, which are used to exalt one individual over another regarding freedoms and opportunities of choice. However, the term is volatile since it supposes economic, cultural, natural or social indicators. However, the literature on human capital seems to converge in terms of values, skills and knowledge acquired by professional training (García, Morales, Bustos, Carreón, Limón and Hernández, 2013).

Even the compliments are part of human capital and talent motivation it is fundamental to a climate of trust, commitment and satisfaction appearance. In this sense, human capital is discursive, although it has a symbolic content; it operates in a peculiar way through motivation and leadership. In principle, human capital means of subsistence, but also the consolidation of a system of symbols that operate in favor of representation, habitus or Prune field r. In effect, human capital is an instrument of objectification, anchoring, inheritance, acquisition and 
construction of symbol scenarios that give power to those who use them (García, Sandoval, Rivera, Limón, 2017).

However, human capital is a fragile instrument because it can be broken if there is a gap of distrust or lack of commitment. Alternatively, it is a means of manipulation that consists of materializing expectations or consolidating collaborative networks from which representations, habitus and fields are woven as discourses around power. In the same way that financial credit operates as a backup of confidence and certainty for business relationships, the credit of knowledge, values and skills given to a group or individual expresses confidence that such person is able to satisfy a need, solve a problem or simply broaden the symbolic gap between groups. That is, it is about human talents that can become leaders of opinion and mobilization in favor of economic, political, social or cultural interests (García, Valdés and Sandoval, 2016).

In the case of migration, human capital attends to the expulsion of talents not only for their knowledge or skills, but for their values of honesty as is the case of day laborers or caregivers who in the market are seen as examples of dedication and effort. In the case of organizations, the values of loyalty and commitment are indispensable requisites for the quality and competitiveness of small and medium-sized enterprises in the face of the insertion of transnationals in the community (Gissi and Soto, 2010).

Both dimensions of human, migratory and entrepreneurial capital seem to approximate since both share values that make migrants and entrepreneurs of Xilitla unique with respect to other communities that saw their young people leave, but did not see them return, or, they observed how The profits of their businessmen were not reinvested in their communities and in the end they were left without natural resources or infrastructure for tourism since their migrants did not return and went from being indigenous peoples to ghost towns without having been magical towns (Guillén, 2010). 
This difference is explained by the generation of opportunities not only for employment, but also for life and personal growth that entails skills and responsibilities. Capacity is the result of freedoms and opportunities while the cause of the generation of social responsibilities. In this sense, the Theory of Economic Capacities assumes that the freedom of choice, diffused by liberal or neoliberal public policies, is the propitious context for the emergence of opportunities that will oblige individuals to perfect or specialize their knowledge and adjust their skills to the market requirements. This implies knowledge of anticipation and understanding of the problems. Above all, in the face of crisis, the selection of the most adaptive elements is necessary to face the challenges of unexpected changes that do not involve conflicts or differences between the parties involved in the competition for resources.. In the case of the groups and their internal differential dynamics, the capacities are a source of stability since the diversity of opportunities generates innovative ideas of which the group (Hernández, Carreón, Morales, Aguilar and García, 2014) will choose the optimum.
Faced with the challenges of the environment, groups seek at all costs to solve their shortcomings through the continuous improvement of skills via training or training, but being an external process, it transforms the dynamics of the group in one way or another. As such, responses to the internal contingency come from diverse knowledge and knowledge, the greater the probability that they will remain in constant competition for the benefit of the group. Thus a group acquires competitive advantages over other similar representation, habitus, field, or capital, but different in terms of freedoms, opportunities, capacities and responsibilities (Iglesias, 2010).

Economic capacities explain group differences in a same community and competition for resources financial or naturals. In the case of migration and entrepreneurship, the capabilities are the result of a series of public policies related to the expulsion of cheap labor and business development for the development of large-scale tourism. It is possible to observe that the migratory economic capacities 
obey a series of intentions and actions under risk in front of the entrepreneurship of productive processes, distributives and logistics under a context of flexibility. Both dimensions deregulated by the State and its business development policies at the expense of reducing labor rights. However, the financial support supposes a minimum planning of the organizations whenever they are adjusted to the objectives of the public programs for entrepreneurs, micro entrepreneurs or merchants around coffee growing. By contrast, the forsaken migration of State assumes risk behaviors that imply a greater probability of improvising the migrant practice, labor insertion, support networks, or, greater possibilities of fraud, extortion or theft of goods. In this sense, the capacities denote habitus of risk and representation of uncertainty for the case of migration and habitus of microfinance, as well as representations of flexibility or alliances between SMEs and transnationals for the case of entrepreneurship (Loyola, and Rivas, 2010).

In summary, both dimensions, migration and business seem to differentiate, but rather are part of the same process that goes from exclusion to inclusion through the marginalization and vulnerability of a Huastec community over two sexiness in which the Public policies contributed to the development of entrepreneurship in the micro region. Precisely, the representations, habitus, fields, capitals and capacities are the indicators of this process that goes from migration to entrepreneurship. The entrepreneurial spirit, whether inherited in the place of origin or acquired in the place of migrant stay, is a process that would culminate in life satisfaction as the remuneration increases or the opportunities diversify. That is, life satisfaction seems to have a link with the entrepreneurial spirit in terms of the search for utility, profit and benefit for a systematic activity that implies a commitment to an organization (Malmod, 2011).

That is why in contexts of uncertainty Mobbing inhibits the satisfaction of life and resignifies the entrepreneurial spirit since human relations undermine the obstacles that represent the relationships of task. In effect, if the relationships between partners overlap with the objectives of the group, then in the 
entrepreneurial spirit emerge dimensions of resilient order in which the individual will develop coping strategies before the inconveniences of working under a climate of tension (Molini and Salgado, 2010).

In such a scenario, the entrepreneurial spirit correlates with styles of transformational leadership in which each of its symptoms are supported by specific innovation actions that disrupt other correct, avoidant or motivating styles . In this sense, human relationships between leaders and subordinates seem to influence individual entrepreneurship rather than collective or group by the mere fact of including self-centered rather than altruistic values. There are also differences between men and women with respect to situations of stress in which the entrepreneurial spirit is inhibited more in the masculine than in the feminine groups. Apparently, the relationships established between men facilitate Noise coping It is in the masculine groups where a climate of trust develops that is more linked to life satisfaction, the main indicator of the entrepreneurial spirit. As tasks involve greater coordi- nation, collaboration among workers increases, but a reduction of it is closer to frustration, although this implies the innovation of ideas as another symptom of entrepreneurship (Nacif, Martinet and Espinosa, 2011).

However, the agreements between leaders seem to affect more the dynamics of labor between subordinates and even encourages them to implement strategies to adjust their actions to the decisions of the high commands. This means that the entrepreneur spirit would also be motivated by the dynamics of decisions and their effects on the job stability of employees. If job satisfaction is the result of a climate of positive tasks and relationships, then the entrepreneurial spirit would have two dimensions. The first dimension would be the product of contexts favorable to the formation of groups, as well as the achievement of objectives while the second would be the result of a series of barriers and obstacles from which creativity and innovation are encouraged (Nozica, 2011). 
However, if the results move away from the established goals, then a series of conflicts that anticipate the change appear the change of paradigm in the interpersonal relations and the way in which the teamwork is carried out. In other cases, the enterprising spirit to correlate spuriously with life satisfaction denotes other factors that would be influencing it since it would be more indicated by factors of impersonal order and close to levels of stress that, far from slowing down the enterprise, credit it as an alternative contingenci to organizational as (Orostegui and Matos, 2009).

In reference to performance and productivity, both dimensions of entrepreneurship announce the incorporation of lifestyles that are developed within organizations as a response to the absence of leadership. This means that when the communication channels are blocked, then the employees adapt to a production pattern that leads them to achieve the goals. This is so because in the workplace there is an economic stability of talents that, faced with the onslaught of problems inherent in top management or recog- nition crises, develop skills, knowledge and values oriented towards process innovation rather than the control of quality. Entrepreneurship is, under the context of conflict, a construction of the needs, expectations and competences of employees (Pérez, 2010).

However, the entrepreneurial spirit also underlies the sense of community, roots and identity around a region, location or space. That is, workers who live in the areas surrounding the organizations are willing to accept working conditions while generating jobs that benefit the community, even if the company takes the biggest profit (Rivera, García and Carreón, 2017).

Identity processes are those that involve entrepreneurship, but also competition for resources. In both cases, the organization commitment to is revealed as an important influence on the performance factor, satisfaction and skills. In those localities where transnational companies implemented knowledge management systems and transferred a production model to the community, labor engagement intensified. 
That is, shared knowledge was generated, but in cases where knowledge was the result of transnational technology and local community participation, the commitment was also increased. Substantially.

The same processes were observed in those cases in which transnational companies implemented knowledge management models in small and medium-sized local companies. Labor commitment seems to have been the main determinant of entrepreneurship, if confidence and innovation were correlated with both variables (Sandoval, Carreón, García, Quintero and Bustos, 2017).

Based on these reviews, it is possible to affirm that entrepreneurship has as essential indicators commitment, trust, innovation, cooperation and resilience. By relating to local culture, community customs and practices, as well as regional identity, the entrepreneurial spirit substantially increased their life satisfaction values (Santamaría, 2012).
However, strategic planning based on international quality standards has resulted in greater productivity and intensification of competitiveness more than hybrid models and alliances between transnationals.

The state of the issue warns about the emergence of entrepreneurship in local contexts from which strategic alliances are formed at the regional and local level in which communities adopt management, production, logistics and sales systems disseminated by multinationals through SMEs or micro-businesses In a context in which business development policies are intensified, the entrepreneurial spirit seems to be a response of the communities that were previously migrants and that are now federal and local investment scenarios, which immersed them in a dynamic on which they built representations, habitus, fields, capitals and capacities oriented to local development (García, 2013). 
Entrepreneurship in a scenario of former migrants and traders involves the objectification and anchoring production management and former migrants adopted in the United States, they appear to have influenced its provisions towards generating Xilitla trade. Once the knowledge in the ex-migrant community and now the merchant was disseminated, its effects on the increase of values, skills and knowledge were observed. At the same time, lifestyles were generated in which the trust and commitment inherited by their relatives in Xilitla, SLP and learned in the USA emanated, which affected their values, skills and knowledge (García, 2017).

However, the objectification and anchoring of the US enterprise in the former migrants of Xilitla required the formation of capital such as cooperation and solidarity at the time of developing the values, knowledge and skills necessary for the survival of the microenterprise. Alternatively, through the freedoms, opportunities and responsibilities; the which, in some way, were developed as discursive fields, social representations affected the generation capabilities-oriented venture. Lastly, the formation of provisions for entrepreneurship influenced investment capacities through discursive groups in which freedom, opportunity and responsibility served as decisive elements for entrepreneurship (Carreón, 2016).

\section{METHOD}

A cross-sectional and correlational study was carried out. A non-probabilistic selection of 300 merchants was carried out, the selection criterion being that they had been migrants.

The Multifactorial Scale of Worker, Entrepreneurial and Transforming Spirit was built, which includes 40 items related to representations, habitus, fields, capitals and capacities in their dimensions of objectification, anchoring, inheritance, apprehension, freedoms, opportunities, responsibilities, cooperation, solidarity, values, skills and knowledge. 
An analysis of normal distribution, reliability, validity, covariance, structure and fit was carried out.

Normality. From the kurtosis parameter in which the values close to the unit denote a distribution in the form of a normal curve, the requirement for the estimation of other parameters and analysis was established. In addition, the level of significance was calculated with the Boostrap statistic whose value should have been significant at 0,000 .

Reliability. We proceeded to establish the internal consistency between items and scale or subscales with the help of Cronbach's alpha in which values higher than 0.60 were considered as evidence of reliable results in different contexts, latitudes or samples. On the other hand, values close to zero were assumed as evidence of a spurious relationship between the item and the subscale, as well as values close to unity as evidence of collinearity or multicollinearity between the reactants and the scale.
Validity. The correlation between factors and items was carried out with the help of above 0,300 factor weights prior exploratory factor analysis and $\mathrm{j}$ is rotating main pro max, adaptation and sphericity. The chi-square statistics close to the unit were assumed as evidence of sphericity according to Bartlett's test and values higher than 6.0 were assumed as evidence of adequacy, according to Kayser Meyer Olkin's test.

Covariation. To establish correlations between the factors, phi parameters were used in which values close to zero were considered as spurious, while those close to the unit were assumed as collinear.

Structuring. With the help of the phi, beta and epsilon parameters, we proceeded to calculate the structural model in which those values close to zero were assumed as spurious while those close to the unit were considered as collinear.

Adjustment. In the case of the explained variance percentages, values higher than 0.20 were considered as adjustment evidence, while the chi square value for 
Table 1. Instrument descriptions

\begin{tabular}{|c|c|c|c|c|c|c|c|c|c|}
\hline $\mathbf{R}$ & M & s & K & A & F1 & F2 & F3 & F4 & F5 \\
\hline$r 1$ & 3.01 & 1.34 & 1.36 & 0.61 & 0.301 & & & & \\
\hline r2 & 2.05 & 1.30 & 1.47 & 0.67 & 0.329 & & & & \\
\hline r3 & 2.09 & 1.25 & 1.51 & 0.71 & 0.456 & & & & \\
\hline r4 & 2.43 & 1.11 & 1.94 & 0.69 & 0.576 & & & & \\
\hline r5 & 3.57 & 1.43 & 1.04 & 0.72 & 0.314 & & & & \\
\hline r6 & 3.81 & 1.89 & 1.06 & 0.68 & 0.457 & & & & \\
\hline r7 & 3.86 & 1.04 & 1.67 & 0.61 & 0.571 & & & & \\
\hline r8 & 3.82 & 1.56 & 1.28 & 0.72 & 0.362 & & & & \\
\hline r9 & 2.57 & 1.38 & 1.41 & 0.73 & & 0.585 & & & \\
\hline r10 & 2.45 & 1.14 & 1.69 & 0.75 & & 0.581 & & & \\
\hline $\mathrm{r} 11$ & 3.61 & 1.45 & 1.31 & 0.69 & & 0.525 & & & \\
\hline $\mathrm{r} 12$ & 3.58 & 1.50 & 1.47 & 0.61 & & 0.515 & & & \\
\hline r13 & 2.57 & 1.69 & 1.41 & 0.75 & & 0.381 & & & \\
\hline r14 & 2.51 & 1.89 & 1.57 & 0.78 & & 0.467 & & & \\
\hline r15 & 2.68 & 1.56 & 1.67 & 0.79 & & 0.524 & & & \\
\hline $\mathrm{r} 16$ & 2.41 & 1.45 & 1.87 & 0.68 & & 0.689 & & & \\
\hline r17 & 2.53 & 1.34 & 1.92 & 0.67 & & & 0.481 & & \\
\hline $\mathrm{r} 18$ & 3.57 & 1.26 & 1.83 & 0.74 & & & 0.462 & & \\
\hline r19 & 3.56 & 1.46 & 1.04 & 0.64 & & & 0.385 & & \\
\hline $\mathrm{r} 20$ & 3.78 & 1.39 & 1.92 & 0.63 & & & 0.581 & & \\
\hline r21 & 2.57 & 1.32 & 1.84 & 0.71 & & & 0.593 & & \\
\hline r22 & 3.90 & 1.34 & 1.31 & 0.69 & & & 0.481 & & \\
\hline r23 & 3.95 & 1.25 & 1.32 & 0.72 & & & 0.584 & & \\
\hline r24 & 3.91 & 1.56 & 1.24 & 0.75 & & & 0.592 & & \\
\hline r25 & 3.56 & 1.67 & 1.30 & 0.70 & & & & 0.651 & \\
\hline r26 & 3.41 & 1.50 & 1.35 & 0.77 & & & & 0.540 & \\
\hline r27 & 3.54 & 1.47 & 1.32 & 0.79 & & & & 0.436 & \\
\hline r28 & 3.23 & 1.60 & 1.32 & 0.75 & & & & 0.431 & \\
\hline r29 & 3.54 & 1.79 & 1.45 & 0.79 & & & & 0.432 & \\
\hline r30 & 3.76 & 1.56 & 1.23 & 0.74 & & & & 0.450 & \\
\hline r31 & 4.13 & 1.54 & 1.15 & 0.75 & & & & 0.536 & \\
\hline r32 & 3.56 & 1.43 & 1.19 & 0.70 & & & & 0.468 & \\
\hline r33 & 3.24 & 1.56 & 1.46 & 0.79 & & & & & 0.651 \\
\hline r34 & 4.01 & 1.89 & 1.34 & 0.68 & & & & & 0.548 \\
\hline r35 & 3.25 & 1.56 & 1.78 & 0.72 & & & & & 0.438 \\
\hline r36 & 3.56 & 1.45 & 1.98 & 0.75 & & & & & 0.396 \\
\hline r37 & 3.45 & 1.57 & 1.89 & 0.74 & & & & & 0.456 \\
\hline r38 & 3.46 & 1.24 & 1.80 & 0.72 & & & & & 0.357 \\
\hline r39 & 4.23 & 1.54 & 1.86 & 0.73 & & & & & 0.546 \\
\hline $\mathrm{r} 40$ & 3.57 & 1.43 & 1.56 & 0.79 & & & & & 0.492 \\
\hline
\end{tabular}

$\mathrm{R}=$ Reactive, $\mathrm{M}=$ Mean, $\mathrm{S}=$ Standard Deviation, $\mathrm{K}=$ Kurtosis, $\mathrm{A}=$ Alpha by removing the value of the item. $\mathrm{N}=300$ Kurtosis Multivariate Mardia $=3.211$, I index of adequacy of the sample $\mathrm{KMO}=0.762$, Test Bartlett sphericity: $\mathrm{X}^{2}[13 \mathrm{gl}]=18.08, \mathrm{p}<0.001$. Extraction method: Main axes. Rotation method: Promax. Percentage of variance explained: F1 $=$ Representations $(18 \%$ of the total variance explained), F2 = Habitus ( $15 \%$ of the total variance explained), F3 = Fields $(11 \%$ of the total variance explained $), \mathrm{F} 4=$ Capitals $(7 \%$ of the total variance explained $), \mathrm{F} 5=$ Capacities ( $3 \%$ of the total variance explained).

Source: Prepared with the study data 
hypothesis testing was assumed to be close to zero evidence of an adjustment. Because the size of the sample has an impact on the chisquared values, the goodness-of-fit indices were estimated in which values close to the unit were considered as evidence of adjustment, while those close to zero for residual rates They were also considered as a good fit.

\section{RESULTS}

Prior to the multivariate analysis, the normal distribution of the responses to the instrument that measured the enterprise and its corresponding dimensions of: representations, habitus, fields, capitals and capacities (see Table 1) was established.

It is possible to observe that the values of kurtosis are close to the unit and that the reliability values are greater than the required minimum of correlation between items and subscales, which reached values higher than necessary. Regarding validity, the results show the prevalence of five factors in which the variance explained exceeded the minimum $20 \%$ for each one (see Table 2). The first factor correspon- ding to the representations was made up of reagents $1,2,3$ and 4 explaining $53 \%$ of the total variance.

The second factor related to habitus is made up of reagents $5,6,7$ and 8 with $45 \%$ of the variance explained while the third factor alluding to the fields was configured with reagents $9,10,11,12$ and 13 14 explaining $39 \%$ of the variance.

The fourth capital factor included items $15,16,17$ and 18 with $32 \%$ of the variance explained while the fifth factor of capacities included items 19, 20, 21, 22, 23 and 24 explaining $27 \%$ of the variance

Regarding the estimation of correlations between factors to establish dependency relationships in the structural model (see T abla 2 ) the results show negative associations between representations and factors habitus, capital and capabilities $(\Phi=-0.671, \Phi=-0.590, \Phi=$ -0.685 respectively). This suggests that the symbols around the entrepreneurial spirit are intensified whenever the dispositions, cooperation, trust, values, skills and knowledge are reduced to their minimum ex- 
Table 2. Correlations and covariances

\begin{tabular}{|c|c|c|c|c|c|c|c|c|c|c|}
\hline & F1 & F2 & F3 & F4 & F5 & F1 & F2 & F3 & F4 & F5 \\
\hline F1 & 1.102 & & & & & 1.873 & 0.549 & 0.691 & 0.674 & 0.941 \\
\hline F2 & $0.671^{*}$ & 1.035 & & & & & 1.754 & 0.592 & 0.603 & 0.538 \\
\hline F3 & $0.481^{*}$ & $0.487^{* *}$ & 1.025 & & & & & 1.986 & 0.594 & 0.673 \\
\hline F4 & $0.590^{*}$ & $0.836^{* \star *}$ & $0.756^{* \star}$ & 1.024 & & & & & 1.760 & 0.596 \\
\hline F5 & $0.685^{* *}$ & $0.481^{*}$ & $0.614^{*}$ & $0.796^{*}$ & 1.071 & & & & & 1.639 \\
\hline
\end{tabular}

Source: Prepared with the study data

pression. This finding is fundamental to explain why entrepreneurship does not develop in authoritarian areas, although it emerges as a resource for subsistence. However, the representations had a positive covariance with the discursive fields $(\Phi=0.481)$ which suggests that the symbols of entrepreneurship are related to freedoms, opportunities and responsibilities acquired in their journey through the US and implemented in Xilitla.

In the case of habitus, whether inherited or acquired, they were positively linked to discursive fields, capitals and capacities $(\Phi=0.487$, $\Phi=0.836, \Phi=0.481$ respectively) .

This means that the provisions are concomitant with freedoms, opportunities and responsibilities, cooperation and trust, values, skills and knowledge, all of them related to the business acquired in the US and implemented in Xilitla. Both relationships between contexts suggest that there is a cycle of provisions that are forming migrants and entrepreneurs in both Xilitla and the US through the networks of workers.

If the habitus were inherited in Xilitla and acquired in the US, then the relationship between an expelling context and another collector of human talent seems not only to be circumscribed to the production and dissemination of symbols through discourses or organizational and psychological resources, but through of the networks of families, friends and acquaintances that move from Xilitla to the US and return with an updated entrepreneurial spi- 
rit that will allow them to insert their microenterprise in the global dynamics of the multinationals when strategic alliances are concerned.

Regarding the discursive fields that are built in reference to freedoms, opportunities and responsibilities of the entrepreneurship of a business to be positively associated with cooperative and trustworthy forms as well as values, skills and knowledge for entrepreneurship $(\Phi$ $=0,856$ and $\Phi=0,614$ respectively) involve close links between migrants who returned from the US, potential migrants in Xilitla, and business partners from other regions for the dissemination of entrepreneurship.

The resources of cooperation and trust in relating to values, skills and knowledge $(\Phi=0.796)$ denote a se-

\section{Table 2. Correlations and covariances}
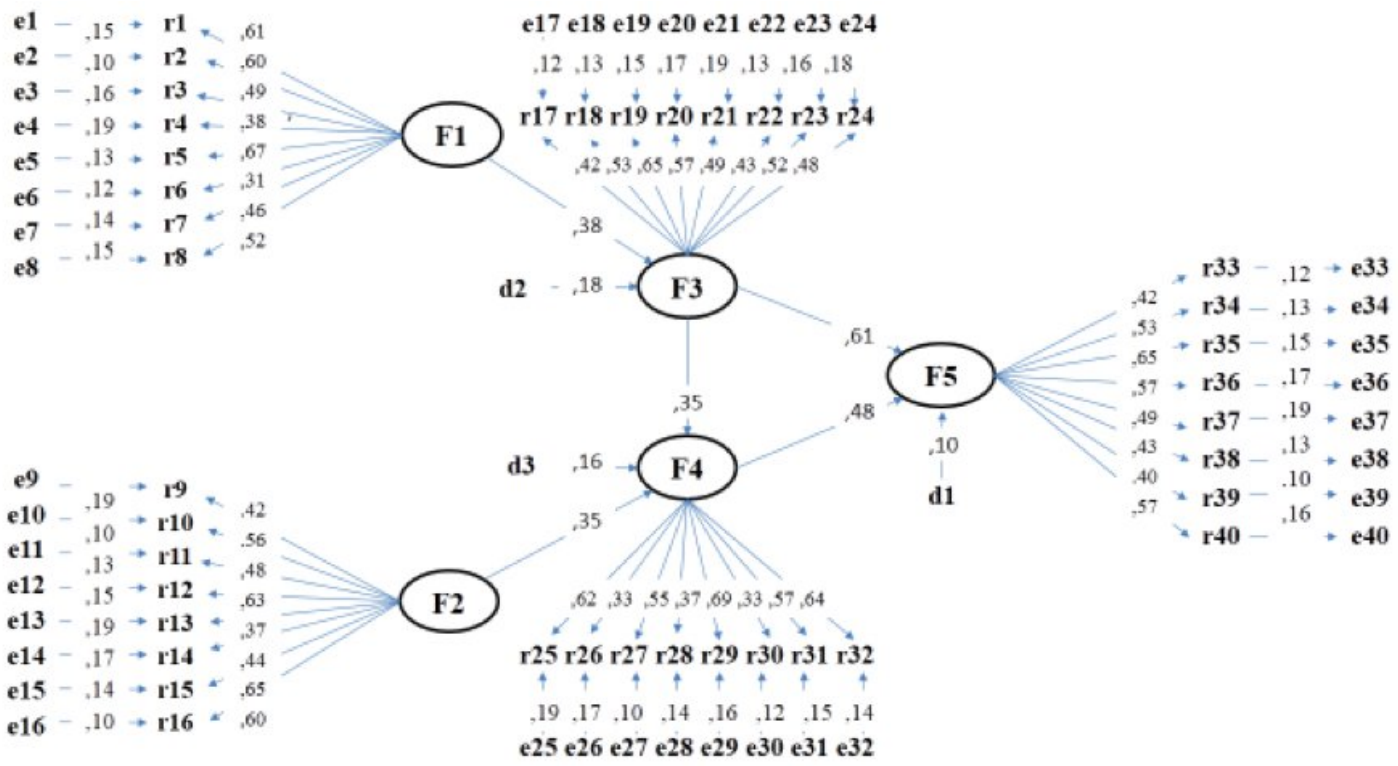

F1 = Representations, F2 = Habitus, F3 = Fields, F4 = Capitals,

F5 = Capacities: $d$ = Disturbance measured factors; $e=$ errors measured indicators: $\leftarrow$ relations between disturbance or error and factor or indicator; $\rightarrow$ relations between factor and indicators

Source: Elaborated with data study 
ries of processes that explain the formation of entrepreneurs in the US with a family business background in Xilitla. The covariances suggest dependency relationships between the factors of the venture and to corroborate this assumption, a structural model was estimated (see Figure 1).

Finally, the hypothesis was tested with the estimation of the adjustment indices since the chi square value was sensitive to the sample $[\mathrm{X} 2=14.21(3 \mathrm{gl}) \mathrm{p}=$ 0.307]. The Adjustment Goodness Index (GFI for its acronym in English) was very close to the unit (0.987) and the residual index (RMR for its acronym in English) close to zero (0.042). Both values plus the percentage of explained variance of each factor, which was higher than $20 \%$, decided the acceptance of the null hypothesis.

\section{DISCUSSIONS AND}

\section{CONCLUSION}

The entrepreneurial spirit that is built in Xilitla in reference to the migration to the US is more determined by dispositions inherited in Xilitla and acquired in the US. This finding clarifies the differences found when explaining the impact of the transnationals on the local economic dynamics. Unlike the strategic alliances that derive in franchises, in Xilitla cooperation and innovation relationships were forged that involve the local government, the migrant community in the US and the microentrepreneurs that returned to Xilitla. It is true that financial differences determine global business models on local needs, but in the case of Xilitla, the community specialized in coffee growing and ecotourism no longer based on a cross-cultural pattern, but of innovation in services and products in such a way that it differed from other neighboring communities.

Between the community history of entrepreneurial spirit in Xilitla and the entrepreneurial knowledge acquired in the US, life satisfaction bursts the process that local development entails when finding that the most enterprising Hindu communities have greater life satisfaction open the discussion around that if the aims of entrepreneurship are merely economic or also involve community development. It is true that coffee growing and ecotourism 
are two instruments for local wellbeing, but they also mean activities favorable to the environment of $\mathrm{Xi}$ litla. This means that community entrepreneurship is far from the globalized entrepreneurial spirit, which supposes the utility and the gain over the regional preservation or the welfare of the communities. It is a logic more anchored to the traditions, uses and customs that are gestated within the peoples. It is through the roots in which the enterprise is molded according to local rather than global needs.

Indeed, the tension between transnational business models with respect to local identity seems to fade as strategic alliances delimit investment and action margins.

That is, external investment can coexist with local entrepreneurship modes even in contingent situations. Moreover, local production implies a greater commitment on the part of the community, which is why it strengthens the bonds of trust with multinational companies whenever there is an inherited and acquired habitus called entrepreneurial spirit.
If the entrepreneurial process that began in Xilitla and was developed in the United States is correct, then it will be possible to observe habitus entrepreneurs, which differentiate them from other localities and surrounding communities. In addition, the impact of the provisions on entrepreneurship would have its observable effects on the values, knowledge and skills for entrepreneurship in the locality.

However, entrepreneurship also underlies situations of uncertainty, risk and scarcity. These are significant differences between leaders and employees in work climates of tension, exclusion and pressure. The assumption according to which entrepreneurship is the product of creativity and innovation, which are responses of individuals and groups to scarcity and conflict, seems to have been corroborated. This implies that, in Xilitla, unlike the economic crises and labor exclusion that prevails in the USA, the fatalistic scenarios of scarcity, conflict and competition for resources are factors that the community still does not experience and therefore it seems not to anticipate. In that sense, the opportunity to manage funds for natural disasters is latent. 
However, the community of Xilitla, SLP, is also exposed to the flight of investments, as there are other locations that compete for tourism and the sale of coffee. In this dynamic, the fatalistic scenarios are more beneficial for local entrepreneurs, since it allows them to anticipate a scarcity of resources or conflicts of interest.

In both cases, stability or financial, ecological or social instability, the entrepreneurial spirit of Xilitla advances towards a scenario in which social reliability could emerge after transparency in the allocation of resources, business development or internal competition oblige authorities to limit investment and deregulate credits to ecotourism trade or organic production.

The entrepreneurial spirit seems to have two dimensions according to the contexts of economic stability or ecological instability. In its inherited and acquired dimension, the $\mathrm{Xi}$ litla enterprise seems to be built from the networks of migrants and microentrepreneurs. In contrast, in its innovative dimension and know- ledge management, the entrepreneurial spirit would be the result of conflicts, tensions, discrepancies, disagreements or disagreements between migrants, microentrepreneurs, authorities and transnational companies when a contingency is approaching or some catastrophe occurred.

Entrepreneurship, as an instrument of local development, is necessarily linked to the governance of natural resources, which consists not only in the transparent allocation of financing and investments, but also implies the concerted and co-responsible participation of the community. In this sense, local economic capacities should not only be circumscribed to ecological values, business knowledge or discursive skills, but also consist in the dissemination of the roots, identity and belonging to the community and the environment of Xilitla, SLP. 


\section{REFERENCES}

Amrouni, $H$. and Abdelwahed, R. (2014). Is entrepreneurship for you? Effects of storytelling ling on entrepreneurall intention. International Journal of Business and Management, 9 (9), 176-192 http://doi.org/ 10.5539 / ijbm.v9n9p176

Berrou, JP and Combaunous, F. (2012). The personal networks of entrepreneurs in a informal African urban economy. Does the strength of ties matter? Review of Social Economy, 1, 1-30

Caballlo, A., Reyes, R. and Solis, P. (2006). The competitive strategy adopted by the transnational company in the global market. Accounting and Administration, 50, 89-122

Carr, J. and Sequeira, J. (2007). Prior family business exposure as intergenerational influenced and entrepreneurial intent: $A$ theory of planned behavior approach. 60 , 1990-1998 http://doi.org/ 10.1016/ j.jbusres.2006.12.016

Carreón, J. (2013). Discourses on labor migration, return and social reincersion based on group identity in Xilitla, micro-region of Huasteca Potosina (Mexico). In L. Cano (coord.). Poverty and social inequality. Challenges for the reconfiguration of social policy. (pp. 153-174). Mexico: UNAM-ENTS
Carreón, J. (2016). Human development: Social entrepreneurship and governance. Mexico: UNAM-ENTS

Carreón, J., De la Cruz, PI and De los Santos, M. (2015). The administration of social fears. Contrasts of a model of perception of insecurity in Mexico. Ehquity, 4, $31-60$

Carreón, J., Hernández, J., Bustos, JM and García, C. (2017). Business promotion policies and their effects on risk perceptions in coffee growers in Xilitla, San Luis Potosí, central Mexico. Poiesis, 32, 33-51

Carreón, J., Hernández, J., Quintero, ML, García, C. and Mejía, S. (2016). Knowledge networks around organizational complexity: learning self-regulation, dissipation, adaptability and dynamism in the face of changes. Prospective, 2 (2), $57-70$

Carreó n, J., Hernández, J., Quintero, M. L., García, C. and Mejía, S. (2016). Knowledge networks around organizational complexity: learning self-regulation, dissipation, adaptability and dynamism between changes. Prospects in Psychology, 2 (2), 5770 
Castiglioni, M., Castro, I. and Galán, JL (2015). The use and choice of multipatner partnerships: an exploratory study. Market Economic \& Business Journal, 45 (1), 95-123 http://doi.org/ $10.7200 /$ esicm.150.0461.2e

Contreras, G. (2012). Networking associations for the socio-digital integration in Andalusia. Journal of Andalusian Studies, 29, 105-126 http://doi.org/ 10.12795 / rea.2012.i29.05

Domínguez, G. and Fuentes, J. (2006). Communication and information as or generators of competitiveness in organizations. Accounting and Administration, 50, 207-230

Economist Intellig en Unit (2010). Women's economy opportunity. London: EUI

Economist Intelligence Unit (2015). Evaluating the environment for public-private partnerships in AsiaPacific. London: EUI

Fernández, V. and Crespo, M. (2011). Resilience, resistant personality and growth in caregivers of people with dementia in the family environment. Science and Health, 22 (1), 21-40

Ferreiro, F. (2013). Woman and entrepreneurship A special reference to business incubators in Galicia. RIPS, 12 (3), 81-101
Fuentes, F. and Sánchez, S. (2010). Analysis of the entrepreneur: a gender perspective. Studies in Applied Economics, 28 (3), 1-28

García, C. (2013). The knowledge network in a university with a system of professional practices and a technological-administrative social service. Fundamentals in Humanities, 14 (1), 135-157

García, C. (2017). Specification of a local entrepreneurship model in migratory flows back to the community of origin. Passages, 5 , 26-39

García, C., Carreón, J. and Hernández, J. (2016). Specification of a sociopolitical complexity model. Political Psychology, 14 (16), 40-59

García, C., Carreón, J. and Hernández, J. (2017). Limits of occupational health models. Study of adherence to the treatment of asthma in elderly migrant workers of the State of Mexico. Management Vision, 16, 103-118

García, C., Carreón, J., Bustos, JM and Hernández, J. (2017).

Theoretical and conceptual frameworks around local development. Margin, 85, 1-11

García, C., Carreón, J., Hernández, J. and Bustos, JM (2017). Institutional power and civil influence in the mediation of social work before policies and social needs. Criticism \& Resistance, 4 , 250-264 
García, C., Carreón, J., Hernández, J. and Salinas. (2016). Governance of the actors and networks of technological innovation. In ML Quintero, Sales, J. and Velázquez, E. B: (coord.). Innovation and technology Challenges for its practical application in companies. (pp. 79-94). Mexico: PorrúaUAEMEX UAP Nezahualcóyotl

García, C., Carreón, J., Hernández, J., Aguilar, JA, Rosas, FJ and Bustos, JM (2015). Differences in reliability against risk, uncertainty and conflict between coffee farmers in Xilitla, Mexico. Eureka, 12 (1), 73-93

García, C., Carreón, J., Hernández, J., Carbajal, C., Quintero, ML, Sandoval, FR and Valdés, O. (2016). Incidence of micro-financing policies on the perception of coffee entrepreneurship and implications for Social Work. Equity, 6, 11-36

García, C., Carreón, J., Hernández, J., Montero, M. and Bustos, J. M: (2012). Systems of political complexity. Social Work Today, 65, 39-48

García, C., Carreón, J., Hernández, J., Montero, M. and Bustos, JM (2012). Systems of political complexity. Social Work Today, 65, 39-48
García, C., Carreón, J., Mecalco, J., Hernández, J., Bautista, M. and Méndez, A. (2014). Complex political systems: Implications for sustainable public security. Actions and Social Investigations, 34, 186216

García, C., Carreón, J., Mecalco, J., Hernández, J., Bautista, M. and Méndez, A. (2014). Complex political systems: Implications for sustainable public security. Actions and Social Investigations, 34, 183206

García, C., Carreón, J., Sánchez, A., Sandoval, F. and Morales, M. (2016). Reliability and validity of an instrument that leadership and educational management. Ehquity, $5,109-130$

García, C., Carreón, J., Sandoval, FR, Bustos, JM and Aguilar, JA (2016). Structure of the work culture in a public health promotion institution. Arequipa, 6 (1), 2 91-304

García, C., Juárez, M., Sandoval, FR and Bustos, JM (2017). A psychological approach to environmental complexity: Specification of a model of community stress and resilience. Community, 14, 75-95

García, C., Morales, ML, Bustos, JM, Carreón, J., Limón, GA and Hernández, J. (2013). Systemic foundations of political complexity. Approaches, 25 (1), 7-23 
García, C., Sandoval, FR, Rivera, BL, Limón, GA (2017).

Complexization of a model for the study of environmental resilience. Without Borders, 10 (25), 1-13

García, C., Valdés, O. and Sandoval, FR (2016). Algorithmic and neguentropic complexity in models that explain social suffering in Mexico City. Margin, 81, 1-6

Gissi, N. and Soto, P. (2010). From stigmatization to neighborhood pride: Appropriation of space and social integration of the Mixtec population in a colony of Mexico City. INVI, 68, 99-118

Guillén, A. (2010). Perspectives of the environment in Venezuela. Notebooks UCAB, 10, 29-55 Hernández, J., Carreón, J., Morales, ML, Aguilar, JA and García, C. (2014). Sociopolitical complexity of public transport. Implications for sustainable local development. Reason and word, 86, $4,49-468$

Iglesias, Á. (2010). Strategic planning as a public management instrument in local government: case analysis. Notebooks of Management, 10, 101-120

Loui, Al., Carpio, J. Vergara, A. (2012). Attitudes of entrepreneurship, need for achievement and the intention to develop a business of students of public universities in metropolitan Lima. Journal of Psychology, 15 (1), 61-81
Loyola, C. and Rivas, J. (2010). Analysis of sustainability indicators for its application in the city. Time and Space, 25, 1-15

Malmod, A. (2011). Logic of occupation in the conformation of the territory. Territorial planning as an instrument of planning. Iberoamerican Urbanism Magazine. $6,18-30$

Manktelow, A. (2014). Guide to emerging markets. London: Economist Intelligence Unit

Martínez, A. (2012). Analysis of business networks and their territorial incidence. Technology transfer, learning and innovation. Journal of Andalusian Studies, 29, 18-58 http://doi.org/: 10.12795 / rea.2012.i29.02

Molini, F. and Salgado, M. (2010). Artificial surface and single family homes in Spain, within the debate between compact and dispersed city. Association of Spanish Geographers Bulletin. 54, 125-147

Nacif, N., Martinet, M. and Espinosa, M. (2011). Between idealization and pragmatism: plans for the reconstruction of the City of San Juan, Argentina. Iberoamerican Urbanism Magazine. 6, 5-17

Nozica, G. (2011). Plan for territorial integration. The desirable scenarios of insertion of the province of San Juan al Mercosur. Revista Iberoamericana de Urbanismo, 6, 43-54 
Obrego, C. (2008). The human dimension of entrepreneurship. Strategic Sciences, 16 (20), 225235

Orostegui, K. and Matos, A. (2009). Behavior of the generation of solid domestic waste in the Chaclayo district. Journal of University Research. 1, 44-51

Relative, JL (2006). The training of administrators in the New international environment.

Accounting and Administration, 50, 124-144

Pérez, G. (2010). Financing of urban-ecological projects through the exchange of carbon credits. Urbano. 22, 7-21

Ramos, L. (2013). Alliances and collaborative networks between the cultural groups of the ethnic arts in Andalucia. Empriia, 15, 26-34 http://doi.org/ 10.5944 / empiria.26.7151

Rivera, BL, García, C. and Carreón, J. (2017). Specification of a comanagement model for water services. Academic Research Without Borders, 10 (25), 1-17

Robles, C , Alviter, LE, Ortega, AO and Martínez, E. (2016). Culture of quality and innovation in the microenterprise. In M. Quintero., Sales, J. and Velázquez, EB (coord.). Innovation and technology Challenges for its practical application in companies. (pp. 1127). Mexico: Porrúa-UAEMEX
Rodriguez, A. (2009). New perspectives to understand business entrepreneurship. Thought and Management, 26, 94-119

Sandoval, FR, Carreón, J., García, C., Quintero, ML and Bustos, JM (2017). Model of the determinants of the perception of risk based on perceived risk and stress in relation to the governance of civil protection. Invurnus, 12 (1), 30-35

Santamaría, R. (2012). The accreditation of a need for housing as a requirement for the transformation of rural land. Redur, 10, 193-206

Urquiza, A. and Cadenas, $\mathrm{H}$. (2015). Socio-ecological systems: Theoretical and conceptual elements for the discussion about water vulnerability. Orda, 208, 1-33 